\title{
A educação infantil em Belo Horizonte no contexto da pandemia de COVID-I 9
}

\section{Children's education in Belo Horizonte in the COVID-I 9 pandemic \\ context}

\section{La educación infantil en Belo Horizonte en el contexto de la pandemia del COVID-I 9}

\author{
Mércia de Figueiredo Noronha Pintol \\ https://orcid.org/0000-0002-4986-9853
}

\begin{abstract}
Resumo: A suspensão das atividades escolares em decorrência da pandemia causada pela COVID-19 suscitou várias dúvidas referentes ao calendário escolar de 2020. Este artigo analisa os desafios e as possibilidades colocados no âmbito das instituições integrantes do Sistema Municipal de Ensino de Belo Horizonte no que concerne às determinações legais $\mathrm{e}$ às ações que garantam os direitos das crianças e a qualidade na educação infantil. A investigação, realizada por meio da apreciação de documentos, busca contribuir com as discussões acerca dos dilemas enfrentados pela educação infantil nesse contexto. Infere-se que a situação de pandemia não pode se sobrepor à garantia do direito à educação de todas as crianças, tendo em vista as especificidades do processo de ensino-aprendizagem dessa faixa etária, bem como a vulnerabilidade social de diversas famílias e o aumento da desigualdade social.
\end{abstract}

Palavras-chave: Educação infantil. Sistema Municipal de Ensino de Belo Horizonte. COVID-19.

Abstract: The interruption of the school activities due to the pandemic caused by the COVID-19 resulted in many doubts regarding the 2020 school calendar. This paper analyzes the challenges and possibilities faced by institutions of the Municipal Education System of Belo Horizonte in relation to the legal determinations and the actions that guarantee children's rights and the quality of the children's education. The investigation, carried out through document analysis, seeks to contribute to the discussions about the dilemmas faced by children's education in such context. The data collected suggest that the pandemic situation cannot override the guarantee of the right to the education of all children, considering the specificities of this age group teaching-learning process, as well as the social vulnerability of several families and the increase in social inequality.

Keywords: Children's education. Municipal Education System of Belo Horizonte. COVID-19.

Resumen: La suspensión de las actividades escolares como consecuencia de la pandemia causada por la COVID19 suscitó varias dudas referentes al calendario escolar de 2020. Este artículo analiza los desafíos y las posibilidades colocadas en el ámbito de las instituciones integrantes del Sistema Municipal de Enseñanza de Belo Horizonte en lo que concierne a las determinaciones legales $y$ a las acciones que garantizan los derechos de los niños y la cualidad en la educación infantil. La investigación, realizada por medio de la apreciación de documentos, busca contribuir con las discusiones acerca de los dilemas enfrentados por la educación infantil en ese contexto.

' Doutora pelo Programa de Pós-Graduação em Educação da Universidade Federal de Minas Gerais. Professora da Rede Municipal de Belo Horizonte. E-mail: mercia.noronha@terra.com.br

Olhar de professor, Ponta Grossa, v. 24, p. I-9, e-15536.058, 2021.

Disponível em <https://revistas2.uepg.br/index.php/olhardeprofessor> 
Se infiere que la situación de pandemia no puede sobreponerse a la garantía del derecho a la educación de todos los niños, teniendo en cuenta las especificidades del proceso de enseñanza-aprendizaje de esa franja etaria, bien como la vulnerabilidad social de diversas familias y el aumento de la desigualdad social.

Palabras-clave: Educación infantil. Sistema Municipal de Enseñanza de Belo Horizonte. COVID-I9.

\section{Introdução}

A educação infantil (EI) constitui o atendimento às crianças em espaços coletivos, antecedendo o ensino fundamental. No Brasil, destina-se às crianças de 0 a 5 anos de idade. A Lei de Diretrizes e Bases da Educação Nacional (LDB - Lei n ${ }^{\circ}$ 9.394/96) incluiu a El no sistema educacional como a primeira etapa da educação básica, ofertada em creches para as crianças de até três anos e em pré-escolas para as crianças de quatro e cinco anos, públicas ou privadas. O seu provimento compete aos municípios, nos sistemas de ensino, levando em conta fatores como garantia do direito, relação público/privado para a oferta, espaço físico, proposta pedagógica, currículo, valorização e formação dos professores.

A Resolução CME/BH $n^{\circ} 001 / 2015$, em seu Art. $1^{\circ}$, determina como finalidade da El o desenvolvimento integral da criança de até 5 anos, em seus aspectos físico, emocional, cognitivo e social, complementando a ação da família e da comunidade. Fazem parte do Sistema Municipal de Ensino de Belo Horizonte (SME/BH) I45 escolas municipais de educação infantil (EMEIS), 60 escolas de ensino fundamental com turmas de educação infantil (EMEFS), 207 creches parceiras e, aproximadamente, 670 escolas privadas (particulares e sem fins lucrativos) que atendem a essa etapa da educação básica. ${ }^{2}$

Diante da declaração da Organização Mundial de Saúde (OMS) de pandemia causada pela COVID-19, em março de 2020, e das disposições da Lei Federal $n^{\circ}$ 13.979/2020 quanto às medidas para enfrentamento da doença, este artigo busca analisar os desafios e as possibilidades colocados no âmbito das instituições de El do SME/BH, em face da suspensão das atividades escolares. Para o estudo, utilizou-se a pesquisa documental como estratégia metodológica para a coleta de dados, envolvendo as principais referências do campo da legislação e das políticas públicas para essa etapa da educação, assim como os documentos produzidos para orientação às instituições no atual contexto.

Com o fechamento das escolas e creches, surgiram questões e dúvidas referentes ao calendário escolar de 2020, sobretudo em função da obrigatoriedade da pré-escola. Entre as questões encaminhadas aos órgãos do SME/BH (Secretaria Municipal de Educação - SMED e Conselho Municipal de Educação - CME), estão: como repor os dias suspensos, caso o período de interrupção se estenda? É possível antecipar férias e recessos escolares? Será viável o ensino a distância na El? Será aceitável flexibilizar a carga horária mínima anual? Será admissível prorrogar o ano letivo para o ano civil subsequente? Ressalta-se que, conforme disposto no inciso II, art. 3 I da LDB, a partir da redação dada

\footnotetext{
${ }^{2}$ Fonte: Secretaria Municipal de Educação (SMED), março/2020.
}

Olhar de professor, Ponta Grossa, v. 24, p. I-9, e-I5536.058, 202I.

Disponível em <https://revistas2.uepg.br/index.php/olhardeprofessor> 
pela Lei $n^{\circ} 12.796 / 2013$, a El será organizada com carga horária mínima anual de 800 horas, distribuída por um mínimo de 200 dias de trabalho educacional. Ainda, a LDB, no $\S 2^{\circ}$ do art. 23 , aponta que o calendário escolar deverá adequar-se às peculiaridades locais, inclusive climáticas e econômicas, a critério do respectivo sistema de ensino, sem com isso reduzir o número de horas letivas previsto nessa lei. A Resolução $\mathrm{CME} / \mathrm{BH} \mathrm{n}^{\circ} 00 \mathrm{I} / 2015$, art. II, determina que compete às instituições organizar, de preferência coletivamente, o calendário escolar, garantindo a carga horária mínima, e que qualquer alteração seja feita com aprovação da comunidade escolar.

Assim, diante da situação de anormalidade e de emergência em saúde pública, estão sendo publicadas várias orientações e determinações legais para nortear as instituições quanto às medidas de suspensão das atividades, bem como reorganizar o calendário escolar de 2020.

Levando em conta essas observações, este artigo elenca documentos produzidos nesse contexto, na perspectiva de elucidar as questões legais e políticas colocadas para a El. Busca-se contribuir com as discussões acerca dos dilemas enfrentados pelas instituições do SME/BH, perante a COVID-19. Para tanto, o artigo está organizado em duas seções subsequentes a esta introdução, além das considerações finais. Primeiramente, é apresentado o histórico de produção desses documentos. Na seção posterior, a partir da análise dos documentos, são discutidas as premissas que orientam o atendimento educacional a essa faixa etária, e são relacionados aspectos importantes para a garantia dos direitos das crianças, dos profissionais e das famílias.

\section{Histórico}

Em 17 de março de 2020, o governo municipal, por meio do Decreto $n^{\circ} 17.298$, definiu as medidas de prevenção e de enfrentamento da epidemia causada pelo coronavírus. Entre elas, foi determinada a suspensão das atividades nas instituições de ensino municipais e instituições de El parceiras da Prefeitura de Belo Horizonte (PBH). Essa medida foi reafirmada na Portaria SMED $n^{\circ}$ 102/2020, promulgada no dia 18 de março.

Ainda no dia 18 foi emitida Nota de Esclarecimento pelo Conselho Nacional de Educação (CNE), apontando a realização de atividades a distância como alternativa para o cumprimento do calendário escolar pelas redes e instituições de educação básica e de educação superior, desde que autorizadas pelos respectivos sistemas de ensino. $O$ documento não menciona a El. Isso porque as atividades não presenciais na El não estão previstas na legislação educacional.

No dia 19 de março, foi publicado, no Diário Oficial do Município, um Ato da Presidência do CME/BH recomendando a suspensão das atividades escolares em todas as instituições de El integrantes do $\mathrm{SME} / \mathrm{BH}$, por tempo indeterminado.

Olhar de professor, Ponta Grossa, v. 24, p. I-9, e-I5536.058, 202 I. 
Em 27 de março, foi emitida Nota de Esclarecimento e Orientações pelo Conselho Estadual de Educação de Minas Gerais (CEE/MG), reafirmando que, para reorganizar seus calendários escolares, as instituições podem propor formas de realização de atividades escolares não presenciais, adotando regime remoto e assegurando as 800 horas de atividade escolar obrigatória ${ }^{3}$. Com relação à El, o documento sugere utilizar o período de reposição para atendimento aos bebês e às crianças com atividades que garantam os direitos de aprendizagem e desenvolvimento previstos no currículo.

No dia $1^{\circ}$ de abril, foi publicada a Medida Provisória $n^{\circ} 934$, que estabelece normas excepcionais para o ano letivo, dispensando a obrigatoriedade do cumprimento do mínimo de dias de efetivo trabalho escolar, desde que cumprida a carga horária mínima anual e observadas as normas a serem editadas pelos respectivos sistemas de ensino.

Em 28 de abril, o CNE aprovou o Parecer CNE/CP n 5/20204 sobre a reorganização dos calendários escolares, com a possibilidade de computar as atividades não presenciais para fins de cumprimento da carga horária mínima anual, em razão da pandemia da COVID-19. A aprovação do parecer pelo CNE precedeu de consulta pública, e vários pesquisadores e entidades da área ${ }^{5}$ enviaram recomendações quanto a não utilização da educação a distância na El e, sobretudo, em relação à defesa do direito à educação equitativa e de qualidade social.

\section{Discussão}

Ao se analisar o parecer do CNE, é possível entender que as contribuições das instituições da área não foram consideradas devidamente. Por um lado, o documento aponta não haver previsão legal para a oferta de EaD na El, mesmo em situação de emergência. Registra, ainda, a possibilidade de flexibilização para reorganização do calendário, ao assinalar a frequência mínima de $60 \%$ da carga horária obrigatória, conforme o inciso IV, artigo 3 I da LDB. Por outro lado, sugere a EaD, ao propor que as escolas desenvolvam atividades denominadas "não presenciais" para os pais realizarem com as crianças em casa,

[...] enquanto durar o período de emergência, garantindo, assim, atendimento essencial às crianças pequenas e evitando retrocessos cognitivos, corporais (ou físicos) e socioemocionais. Deste modo em especial, evitaria a necessidade de

\footnotetext{
${ }^{3}$ As escolas que integram os sistemas municipais estão vinculadas às orientações do CNE. Não estão vinculadas às orientações do CEE-MG, mas podem segui-las, desde que sejam determinadas por meio de ato normativo próprio.

${ }^{4}$ A té a data de finalização deste artigo, 18 de maio de 2020, o Parecer CNE/CP n ${ }^{\circ}$ 5/2020 aguardava homologação pelo Ministério da Educação (MEC).

${ }^{5}$ Entre elas: ANPED, Rede Nacional Primeira Infância, Movimento Interfóruns de Educação Infantil do Brasil (MIEIB), Campanha Nacional pelo Direito à Educação.
} 
reposição ou prorrogação do atendimento ao fim do período de emergência [...] (BRASIL, 2020e, p. 9).

E, ainda, "[...] a escola, por sua vez, poderá definir a oferta do instrumento de resposta e feedback, caso julgue necessário” (BRASIL, 2020e, p. I0). Ou seja, trata-se de um documento incoerente e mal redigido. Não considera as especificidades da El e apresenta contradições, uma vez que coloca todas as possibilidades para reorganização dos calendários, dando margem a várias interpretações pelos sistemas de ensino e pelas escolas.

A legislação vigente ${ }^{6}$, que normatiza a política de El e o direito das crianças e das famílias à educação, direciona ações de atendimento que garantam a proteção à infância e as especificidades dessa faixa etária. As Diretrizes Curriculares Nacionais para a Educação Infantil (Resolução CNE/CEB n 05/2009), a Base Nacional Comum Curricular - BNCC (Resolução CNE/CP n 2/2017) e as Proposições Curriculares para a Educação Infantil de Belo Horizonte definem os princípios para a elaboração da proposta pedagógica e do currículo a ser desenvolvido nas instituições, compreendendo as funções de cuidar/educar como a premissa que caracteriza essa etapa educacional e a ocupação do profissional que com ela trabalha, ou seja, o professor com formação em Pedagogia. Nesses documentos, consta que as práticas pedagógicas que compõem a proposta curricular devem ter como eixos norteadores as interações e a brincadeira.

Portanto, a concepção de El presente na base legal pressupõe o relacionamento dos professores com as crianças, mediado por um conhecimento especializado e com intencionalidade, 0 que não condiz com a proposta de educação a distancia, seja por meio de apostilas ou de atividades com o uso da Internet, e desenvolvidas pelos pais ou familiares.

Quanto às escolas públicas e creches parceiras da $\mathrm{PBH}$, imediatamente à suspensão das atividades, a administração municipal iniciou a distribuição de cestas básicas às famílias dos estudantes em substituição à alimentação escolar, com o objetivo de assegurar este direito às crianças e aos adolescentes enquanto durar o período de pandemia. Nesse período, a SMED organizou um espaço on-line de interação com a comunidade escolar. A página, disponibilizada no site da secretaria, conta com sugestões de leituras, filmes, cursos, lives, jogos e brincadeiras. É, também, um ambiente para a divulgação das experiências das instituições, e algumas escolas estão produzindo vídeos com mensagens, compartilhando as rotinas dos professores durante o isolamento social, que são enviados às famílias ${ }^{7}$.

\footnotetext{
${ }^{6} \mathrm{CF}, \mathrm{LDB}, \mathrm{ECA}, \mathrm{PNE}$, Resolução CME/BH nº 00I/20I5.

${ }^{7}$ Disponível em: prefeitura.pbh.gov.br/programas-e-projetos/educacao. Acesso: 28 abr. 2020.
} 
Para as escolas particulares, sobretudo, concomitantemente às determinações legais, os sindicatos e outros órgãos representantes dessa rede vêm orientando escolas e profissionais quanto à reorganização dos calendários escolares, contratos e questões trabalhistas.

Cabe salientar a competência e a autonomia dos sistemas municipais de ensino e de seus órgãos normativos - os conselhos municipais de educação - para regulamentarem a $\mathrm{El}$, de acordo com a legislação nacional e as diretrizes do CNE, em regime de colaboração federativa. Assim, destaca-se a necessidade de normatização complementar referente à reorganização do calendário escolar de 2020 a ser emanada pelo $\mathrm{CME} / \mathrm{BH}$, levando em conta, inclusive, as peculiaridades das redes pública e privada de El de Belo Horizonte e, até mesmo, a diversidade entre as escolas particulares.

Entende-se que é importante considerar as especificidades do processo de ensinoaprendizagem dessa faixa etária, bem como a valorização profissional dos professores que atuam nessa etapa da educação. Nomeadamente, no atual contexto de retrocessos e perdas de direitos, e em meio às medidas de prevenção à COVID-19 com o distanciamento social, evidenciam-se alguns aspectos:

- $\mathrm{A} E \mathrm{ED}$ não é adequada na El. De acordo com a Sociedade Brasileira de Pediatria ${ }^{8}$, a exposição das crianças pequenas às telas é prejudicial à saúde, podendo causar vários transtornos, entre eles a dependência digital, comprometendo o processo de aprendizagem e desenvolvimento.

- A legislação vigente não autoriza a EaD na El, uma vez que o currículo nessa etapa não se organiza por conteúdos escolares, mas na articulação das experiências e dos saberes das crianças com os conhecimentos culturais, artísticos, ambientais, científicos e tecnológicos.

- $\mathrm{A} E \mathrm{ED}$ é uma modalidade educacional regulamentada, diferentemente do que o CNE propõe denominando "atividades remotas" e "atividades não presenciais", arranjadas em um momento de crise, sem as condições de tecnologia e informação adequadas, e contribuindo para a precarização do trabalho docente. Além disso, há a possibilidade de mercantilização ainda maior da educação pública com a entrada de grandes grupos empresariais por meio, por exemplo, de plataformas digitais, material apostilado e cursos de formação para os professores, em contraposição à gestão democrática.

- As condições de igualdade de acesso e permanência nas instituições são imprescindíveis para a concretização dos direitos das crianças e para a qualidade social na El. Considerando a heterogeneidade das famílias e das crianças, sobretudo as mais vulneráveis, e que nem todos possuem recursos para realizar as atividades em casa, não há garantia de equidade educacional por meio de atividades não presenciais no atual contexto.

\footnotetext{
${ }^{8}$ Ver Manual de Orientação: \#Menos telas \#mais saúde. Sociedade Brasileira de Pediatria. Dez./2019.
} 
- O processo indissociável de cuidar/educar que caracteriza essa etapa educacional é complementar às ações das famílias. Desse modo, as interações e brincadeiras mediadas pelos professores nas instituições são diferentes daquelas vivenciadas no contexto familiar.

- É fundamental a flexibilização do calendário escolar, considerando a possibilidade da redução da carga horária anual, de acordo com o inciso IV, art. 3I da LDB. Para isso, ressaltam-se dois aspectos: o primeiro refere-se ao $\S 4^{\circ}$, art. $5^{\circ}$ das Diretrizes Curriculares Nacionais para a Educação Infantil ao determinar que a frequência na El não constitua pré-requisito para a matrícula no ensino fundamental. $O$ segundo diz respeito ao inciso I, art. 3 I da LDB, ao estabelecer que a avaliação na El seja mediante acompanhamento e registro do desenvolvimento das crianças, sem o objetivo de promoção, mesmo para o acesso ao ensino fundamental. Ademais, é preciso ter em conta que o ano letivo não necessariamente precisa coincidir com o ano civil para cumprimento do calendário escolar.

\section{Considerações finais}

Em síntese, neste momento excepcional de uma pandemia em curso, em que as atividades escolares estão suspensas, é imprescindível que sejam emanadas, pelos órgãos competentes, regulamentações efetivas, que considerem os princípios da El e o direito das crianças, famílias e profissionais.

Entre as ações possíveis, são importantes as atuações voltadas à sobrevivência das famílias, sobretudo das redes pública e parceira, engendradas pelas políticas intersetoriais. São válidas também recomendações que poderão ser enviadas às famílias com o objetivo de fortalecer os vínculos afetivos entre crianças e adultos. Essas orientações não podem ser consideradas para cômputo da carga horária. Outra ação plausível é a interlocução entre os vários setores para a construção de propostas de retorno. Já na ocasião da volta às instituições, a preocupação inicial precisará ser com a acolhida de profissionais, crianças e famílias, com segurança. A comunidade escolar, em um processo democrático e participativo, deverá decidir coletivamente sobre a reorganização do calendário, na perspectiva da qualidade e da educação como direito. Desse modo, é razoável inferir que a situação de pandemia não pode se sobrepor à garantia do direito à educação de todas as crianças, tendo em vista, inclusive, a vulnerabilidade social de diversas famílias e o aumento da desigualdade social.

Não obstante as reflexões apontadas neste artigo, outras questões ainda são pertinentes, como por exemplo: como ampliar a capacidade protetiva da escola durante e depois da pandemia? Portanto, diante de tantos desafios, faz-se necessário ampliar os estudos sobre essa temática, avaliando momentos posteriores aos que estiveram na base desta investigação.

Olhar de professor, Ponta Grossa, v. 24, p. I-9, e-I5536.058, 202 I.

Disponível em <https://revistas2.uepg.br/index.php/olhardeprofessor> 


\section{Referências}

BELO HORIZONTE. Conselho Municipal de Educação. Ato da Presidência do CME/BH n 002/2020, de 19 março 2020. Interrupção das atividades escolares nas escolas públicas municipais e privadas de Educação Infantil, integrantes do Sistema Municipal de Ensino de Belo Horizonte. Diário Oficial do Município, Belo Horizonte, 2020a. Disponível em: <www.pbh.gov.br>. Acesso em: 20 mar. 2020.

BELO HORIZONTE. Conselho Municipal de Educação. Resolução CME/BH n00I/2015, de 19 março 2015. Fixa normas para o funcionamento de instituições de educação infantil do Sistema Municipal de Ensino de Belo Horizonte (SME/BH). Diário Oficial do Município, Belo Horizonte, 2015. Disponível em: <www.pbh.gov.br>. Acesso em: 20 mar. 2020.

BELO HORIZONTE. Decreto $n^{\circ}$ 17.298, de 17 março 2020. Dispõe sobre medidas temporárias de prevenção ao contágio e de enfrentamento e contingenciamento, no âmbito do Poder Executivo, da epidemia de doença infecciosa viral respiratória causada pelo agente Coronavírus - COVID-I9.

Diário Oficial do Município, Belo Horizonte, 2020b. Disponível em: <www.pbh.gov.br>. Acesso em: 20 mar. 2020.

BELO HORIZONTE. Secretaria Municipal de Educação. Portaria SMED n 102/2020, de 18 março 2020. Dispõe sobre interrupção das atividades escolares nas escolas municipais e creches parceiras, integrantes do Sistema Municipal de Ensino, em razão de epidemia causada pelo Coronavírus COVID-19. Diário Oficial do Município, Belo Horizonte, 2020c. Disponível em: <www.pbh.gov.br>. Acesso em: 20 mar. 2020.

BELO HORIZONTE. Secretaria Municipal de Educação. Proposições Curriculares para a Educação Infantil: desafios da formação. Belo Horizonte: Prefeitura Municipal de Belo Horizonte, 2013.

BRASIL. Conselho Nacional de Educação. Nota de esclarecimento - COVID-19, de 18 mar. 2020. Brasília, 2020a. Disponível em: <http://portal.mec.gov.br/conselho-nacional-deeducacao/divulgacao>. Acesso em: 05 abr. 2020.

BRASIL. Conselho Nacional de Educação. Resolução CNE/CEB n 5/2009. Fixa as Diretrizes Curriculares Nacionais para a Educação Infantil. Diário Oficial da União, Brasília, 2009. Disponível em: <http://portal.mec.gov.br/index.php?option=com_docman\&view=download\&alias=2298rceb005-09\&category_slug=dezembro-2009-pdf\&ltemid=30192>. Acesso em: 5 abr. 2020.

BRASIL. Conselho Nacional de Educação. Resolução CNE/CP $\mathbf{n}^{\circ}$ 2, de 22 dez. 20I 7. Institui e orienta a implantação da Base Nacional Comum Curricular, a ser respeitada obrigatoriamente ao longo das etapas e respectivas modalidades no âmbito da Educação Básica. Brasília, 20I7. Disponível em: <http://portal.mec.gov.br/index.php?option=com_docman\&view=download\&alias=7963I -rcp00217-pdf\&category_slug=dezembro-2017-pdf\&ltemid=30| 92>. Acesso em: 5 abr. 2020.

BRASIL. [Constituição (1988)]. Constituição da República Federativa do Brasil: promulgada em 5 de outubro de 1988. Brasília, 1988. Disponível em: <www.planalto.gov.br>. Acesso em: 5 abr. 2020.

BRASIL. Lei $n^{\circ}$ 8.069, de 13 julho de 1990. Estatuto da Criança e do Adolescente. Diário Oficial da União, Brasília, 1990. Disponível em: <www.planalto.gov.br>. Acesso em: 5 abr. 2020. 
BRASIL. Lei n 9.394, de 20 dez. 1996. Lei de Diretrizes e Bases da Educação Nacional. Diário Oficial da União, Brasília, 1996. Disponível em: <www.planalto.gov.br>. Acesso em: 5 abr. 2020.

BRASIL. Lei $n^{\circ}$ 12. 796, de 4 abril 2013. Altera a Lei $n^{\circ}$ 9.394, de 20 de dezembro de 1996, que estabelece as diretrizes e bases da educação nacional, para dispor sobre a formação dos profissionais da educação e dar outras providências. Diário Oficial da União, Brasília, 2013. Disponível em: $<w w w . p l a n a l t o . g o v . b r>$. Acesso em: 5 abr. 2020.

BRASIL. Lei n 13.005, de 25 jun. 20I4. Aprova o Plano Nacional de Educação - PNE e dá outras providências. Diário Oficial da União, Brasília, 20l4. Disponível em: <www.planalto.gov.br>. Acesso em: 4 abr. 2020.

BRASIL. Lei $n^{\circ}$ 13.979, de 06 fev. 2020. Dispõe sobre as medidas para enfrentamento da emergência de saúde pública de importância internacional decorrente do coronavírus responsável pelo surto de 2019. Diário Oficial da União, Brasília, 2020b. Disponível em: <www.planalto.gov.br>. Acesso em: 4 abr. 2020.

BRASIL. Medida provisória $\mathrm{n}^{\circ}$ 934, de $\mathrm{I}^{\circ}$ abril 2020. Estabelece normas excepcionais sobre $\mathrm{o}$ ano letivo da educação básica e do ensino superior decorrentes das medidas para enfrentamento da situação de emergência de saúde pública de que trata a Lei $n^{\circ}$ 13.979, de 6 de fevereiro de 2020. Diário Oficial da União, Brasília, 2020d. Disponível em: <http://www.planalto.gov.br/ccivil_03/_ato2019-2022/2020/mpv/mpv934.htm>. Acesso em: 4 abr. 2020.

BRASIL. Ministério da Educação. Parecer CNE/CP n5/2020. Reorganização do Calendário Escolar e da possibilidade de cômputo de atividades não presenciais para fins de cumprimento da carga horária mínima anual, em razão da Pandemia da COVID-19. Brasília, 2020e. Disponível em: $<$ http://portal.mec.gov.br/index.php?option=com_docman\&view=download\&alias $=1450 \mathrm{II}$-pcp00520\&category_slug=marco-2020-pdf\&ltemid=30192>. Acesso em: 5 maio 2020.

DIRECTOR-GENERAL'S opening remarks at the media briefing on COVID-I9 - II march 2020. World Health Organization. Genebra, II mar. 2020. Disponível em: $<$ https://www.who.int/dg/speeches/detail/who-director-general-s-opening-remarks-at-the-mediabriefing-on-covid-19-I I-march-2020>. Acesso em: 4 abr. 2020.

MINAS GERAIS. Conselho Estadual de Educação. Nota de esclarecimento e orientações 01/2020, de 27 mar. 2020. Belo Horizonte, 2020. Disponível em: <https://drive.google.com/file/d/IZg_iPGLzUYJAUkP92latpgtcuBycf08e/view>. Acesso em: 4 abr. 2020.

SOCIEDADE BRASILEIRA DE PEDIATRIA. Manual de Orientação. \#Menos telas \#Mais saúde. Rio de Janeiro, 2019. Disponível em: <sbp.com.br/publicacoes>. Acesso em: 4 abr. 2020.

Recebido em: 25 de maio de 2020.

Versão corrigida recebida em: 29 de setembro de 2020.

Aceito em: 03 de novembro de 2020.

Publicado online em: II de junho de 2021.

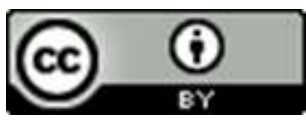

Olhar de professor, Ponta Grossa, v. 24, p. I-9, e-I5536.058, 202 I.

Disponível em <https://revistas2.uepg.br/index.php/olhardeprofessor> 